\title{
Olea europaea Bitki Ekstrelerinin Türkiye'den Elde Edilmiş Leishmania tropica İzolatına Antileishmanial Etkisinin Araştırılması
}

\section{The Investigation of Antileishmanial Activity of Olea europaea Plant Extracts Against Leishmania tropica Isolates from Turkey

\author{
Ahmet Özbilgin*๑, İbrahim Çavuş*๑, Çağlar Çelebi** $\odot$, Morteza Haghi*๑, Cumhur Gündüz**๑ \\ Hüsniye Kayalar*** ${ }^{\infty}$
}

*Manisa Celal Bayar Üniversitesi Tıp Fakültesi, Tıbbi Parazitoloji Anabilim Dalı, Manisa, Türkiye

**Ege Üniversitesi Tıp Fakültesi, Tıbbi Biyoloji Anabilim Dalı, İzmir, Türkiye

***Ege Üniversitesi Eczacılık Fakültesi, Farmakognozi Anabilim Dalı, İzmir, Türkiye

Alındığı tarih / Received:

08.11.2019 / 08.November.2019

Kabul tarihi / Accepted:

02.01.2020 / 02.January.2020

Yayın tarihi / Publication date:

30.09.2020 / 30.September.2020

\section{ORCiD Kayıtları}

A. Özbilgin 0000-0003-3613-8741

i. Çavuş 0000-0002-3860-0146

C. Çelebi 0000-0002-2858-8526

M. Haghi 0000-0001-7765-2662

C. Gündüz 0000-0002-6593-3237

H. Kayalar 0000-0001-7882-0517

icvs26@yahoo.com

Atıf: Özbilgin A, Çavuş İ, Çelebi Ç, Haghi M. Gündüz C. Kayalar H. Olea europaea bitki ekstrelerinin Türkiye'den elde edilmiş Leishmania tropica izolatına antileishmanial etkisinin araştırılması. Turk Mikrobiyol Cemiy Derg. 2020;50(3):141-7.

\section{öz}

Amaç: Dünyada yaklaşık 1 milyar insanın leishmaniasis riski altında olduğu ve leishmaniasis bildirimi yapan 200 ülke olduğu Dünya Sağlık Örgütü tarafından bildirilmektedir. En sık görülen formu olan kutanöz leishmaniasis tedavisinde ülkemizde meglumin antimonat, sodyum stiboglukonat ve son yıllarda amfoterisin B ilaçları kullanılmaktadır. Kullanılan ilaçların toksik etkisinin yüksek ve maliyetli olması yanı sıra son yıllarda meglumin antimonat ve sodyum stiboglukonat ilaçlarına karşı direnç geliştiği bildirilmektedir. Leishmaniasis tedavisinde kullanılmak üzere yeni ilaç adaylarına gereksinim vardır. Çalışmamızda, Olea europaea bitkisinin yaprak ve meyve kısımlarının su, sulu etanol ve kloroform çözücülerinde hazırlanmış ekstrelerinin Leishmania tropica parazitine karşı duyarlılığının in vitro araştırılması amaçlanmıştır

Yöntem: Manisa Celal Bayar Üniversitesi Tıp Fakültesi Parazit Bankası'nda MHOM/TR/2012/CBCL-LT kodu verilerek korunan Leishmania tropica izolatının Olea europaea bitkisinin ekstrelerine karşı in vitro olarak antileishmanial aktivitesi XTT ve hemositometre yöntemiyle araştırılmıştır. Ayrıca bitki ekstrelerinin sitotoksik aktiviteleri incelenmiştir.

Bulgular: Antileishmanial aktivitenin değerlendirilmesinde yaprak su ekstresinin IC değeri $6.77 \mathrm{mg} / \mathrm{kg}$, yaprak sulu etanol ekstresinin IC $C_{50}$ değeri $2.45 \mathrm{mg} / \mathrm{kg}$, yaprak kloroform ekstresinin $I C_{50}$ değeri $6.50 \mathrm{mg} /$ $\mathrm{kg}$, meyve sulu etanol ekstresinin IC $C_{50}$ değeri $4.16 \mathrm{mg} / \mathrm{kg}$ ve meyve kloroform ekstresinin IC $C_{50}$ değeri 0.23 $\mathrm{mg} / \mathrm{kg}$ olarak belirlenmiş ve meyve su ekstresinin antileishmanial etkisinin istatiksel olarak anlamli diğerlerinin ise anlamsız olduğu görülmüştür. Sonuçların ilaçsız kontrol grubu ile istatistiksel olarak karşılaştırılmasına göre meyve klorofm ekstresinin $(p<0.05)$ antileishmanial etki gösterdiği diğer ekstrelerinin anlamsız olduğu görülmüştür ( $p>0.05)$. Olea europaea bitkisinin yaprak su ekstresi $\left(L C_{50} 58.45\right.$ $\mu \mathrm{g} / \mathrm{ml}$ ) dışındaki ekstreler sitotoksik aktivite göstermemiştir.

Sonuç: Bu çalışmamızın sonucunda, Olea europaea bitkisinin meyve kloroform ekstresinin antileishmanial aktivite göstermesi projenin amacı olan antileishmanial etken maddeler saptanması konusunda önemli ve ümit verici bir gelişme olarak değerlendirilmektedir.

Anahtar kelimeler: Olea europaea, kutanöz leishmaniasis, direnç testleri, antileishmanial, Türkiye

\section{ABSTRACT}

Objective: Meglumine antimonate, sodium stibogluconate and amfoterisin B are used in the treatment of cutaneous leishmaniasis which is the most common form in Turkey. Beside being highly toxic and costly, Leishmania parasites also have been reported to have developed resistance against meglumine antimonate and sodium stibogluconate in recent years. In this study, we aimed to investigate the in vitro susceptibility of water, aqueous ethanol and chloroform extracts of the leaves and fruits of Olea europaea against Leishmania tropica parasites.

Method: In vitro antileishmanial activities of Olea europaea plant extracts against Leishmania tropica isolates obtained from Manisa Celal Bayar University Faculty of Medicine with MHOM/TR/2012/CBCL-LT code, were investigated by using XTT and hemocytometer methods. Cytotoxic activities of plant extracts were also determined.

Results: Evaluation of antileishmanial activity showed that water of the aqueous ethanol and chloroform extracts of the leaves, and aqueous ethanol and chloroform extracts of the fruits had $I C_{50}$ values as 6.77 $\mathrm{mg} / \mathrm{kg}, 2.45 \mathrm{mg} / \mathrm{kg}, 6.50 \mathrm{mg} / \mathrm{kg}, 4.16 \mathrm{mg} / \mathrm{kg}, 0.23 \mathrm{mg} / \mathrm{kg}$ respectively. The water extract of fruits did not show any antileishmanial activity. Based on statistical comparison of these results with the control group, it was observed that fruit extract $(p<0,05)$ showed no antileishmanial effect $(p>0,05)$. Extracts other than leaf water extract $\left(L C_{50} 58.45 \mathrm{\mu g} / \mathrm{ml}\right)$ of Olea europaea showed no cytotoxic activity.

Conclusion: As a result of this study chloroform extract of the fruits of Olea europaea ws found to have antileishmanial activity and this can be considered as an important and promising development in determination of antileishmanial active substances which was the main aim of this study.

Keywords: Olea europaea, cutaneous leishmaniasis, resistance tests, antileishmanial, Turkey 


\section{Giriş̧}

Leishmaniasis, Dünya Sağlık Örgütü tarafından önemsenmeyen tropikal hastalıklardan biri olarak kabul edilmektedir. Bugün tüm dünyada toplam leishmaniasis bildirimi yapan 200 ülke ve endemik bölgede yaşayan 1 milyar insan leishmaniasis riski altındadır. Son 5 yılda 1 milyon kutanöz leishmaniasis (KL) olgusu, yılda 300.000 visseral leishmaniasis (VL) olgusu bildirilmektedir. VL'ye bağlı yıllık ölüm sayısının yaklaşık 20.000 olduğu bildirilmektedir ${ }^{(1)}$. Son yıllarda komşu ülkelerde meydana gelen siyasi karışıklık ve savaş nedeniyle ülkemizde meydana gelen göç hareketinden dolayı olgu ve odaklarda önemli oranda artış görülmektedir. Bu durum önümüzdeki yıllarda bu sağlık sorununda ciddi artışlar olabileceğini düşündürmektedir.

Kutanöz leishmanisis tedavisinde ülkemizde meglumin antimonat (Glucantime ${ }^{\circledR}$ ) ve sodyum stiboglukonat (Pentostam ${ }^{\circledR}$ ) ilaçları kullanılmaktadır. Son yıllarda bu ilaçlara karşı direnç olduğu bildirilmektedir. Bu nedenle leishmaniasis tedavisinde kullanılmak üzere yeni ilaç adaylarına gereksinim vardır.

Olea europaea olarak bilinen zeytin ağacı, Akdeniz bölgesi ülkelerinde, Avrupa'nın güneyinde, Kuzey Afrika'da ve ülkemizde ılıman sahil kesimlerinde yetişen ve antik çağlardan beri tıbbi amaçla kullanılan her daim yeşil yapraklı, yaprakları kısa ve geniş, eliptik şekilde olan sığ, kurak ve kireç bakımından zengin topraklarda yetişen bir bitkidir. Eski Mısırlılar mumyalama sürecinde, Yunanlılar ve diğer kültürler ateşe karşı bir ilaç olarak kullanmışlardır. King'in Amerikan İlaç Kodeksi'nin 1898 yılı yayınında zeytin yaprağının kaynatılması ile elde edilen sıvının, vücut sıcakIığını düzenlemeye yardımcı olduğu belirtilmiştir. Son yüzyılda, hem hayvanlar hem de insanlar üzerinde zeytin yaprağı ekstresinin virüslere, bakterilere, mayalara ve parazitlere karşı güçlü antimikrobiyal özellikler sergilediği rapor edilmiştir. Buna ek olarak, zeytin yaprağı ekstresinin kardiyovasküler, hipoglisemik ve antioksidan aktiviteye sahip olduğu bildirilmiştir ${ }^{(2,3)}$.
Leishmaniasis tedavisinde kullanılabilecek yeni etken madde ve yeni ilaç adaylarının araştııı Iması amacıyla çalışmamızda, O. europaea bitkisinin yaprak ve meyve kısımlarının su, sulu etanol ve kloroform çözücülerinde hazırlanmış ekstrelerinin Leishmania tropica parazitine karşı duyarlılığının in vitro araştırılması amaçlanmıştır.

\section{GEREÇ ve YÖNTEM}

Olea europaea Bitkisinin Toplanması: O. europaea bitkisi ülkemizde ılıman sahil kesimlerinde yetişmektedir. Çalışmamızda kullandığımız O. europaea bitkisinin yaprak ve meyveleri İzmir ilimizden, 38.7817 enlem ve 27.0271 boylam koordinatlarına ait bölgeden toplanmıştır (Resim 1).

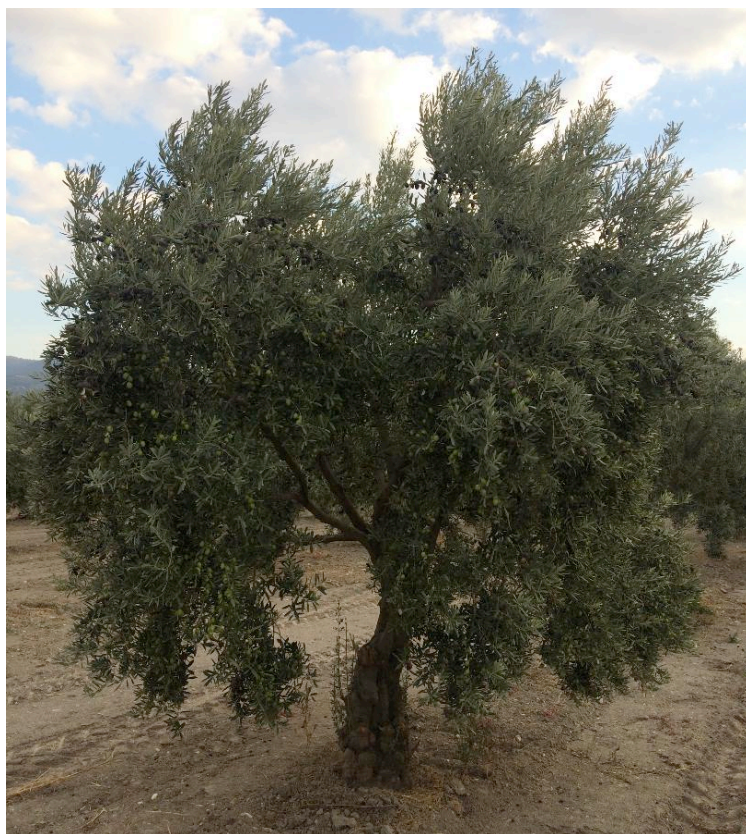

Resim 1. Olea europaea bitkisi.

Olea europaea bitkisinin ekstrelerinin hazırlanması: Toplanan O. europaea bitkisinin yaprak ve meyveleri uygun koşullarda kurutulmuş ve kurutulan materyaller değirmende toz hâline getirilmiştir. $O$. europaea bitkisinin su, sulu etanol ve kloroform ekstreleri çıkartılmıştır.

Su ekstresi: Toz haline getirilen $2 \mathrm{~g}$ bitkisel materyal $100 \mathrm{ml}$. kaynamış su içinde 10 dakika bekletilip sıcak- 


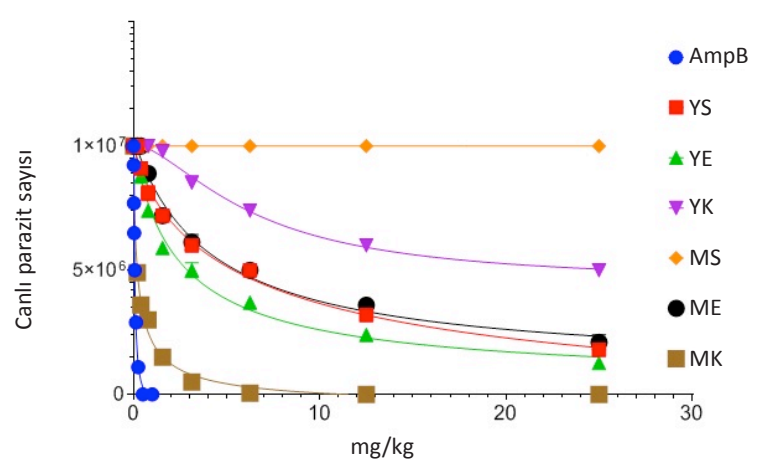

Grafik 1. Olea europaea bitkisinin yaprak ve meyve kısımlarının su, sulu etanol ve kloroform çözücülerinde hazırlanmış ekstrelerinin antileishmanial etki grafiği.

(AmpB: Amphotericin B; YS: Yaprak Su Ekstresi; YE: Yaprak Sulu Etanol Ekstresi; YK: Yaprak Kloroform Ekstresi; MS: Meyve Su Ekstresi; ME: Meyve Sulu Etanol Ekstresi; MK: Meyve Kloroform Ekstresi).

ken süzgeç kağıdı kullanılarak süzülmüştür. Süzülen kısım alçak basınçta rotavaporda $50^{\circ} \mathrm{C}^{\prime}$ yi geçmeyen sıcaklıkta kurutulmuştur. Daha sonra $-80^{\circ} \mathrm{C}^{\prime}$ de dondurulup liyofilize edilmiş ve liyofilize edilen materyal $-20^{\circ} \mathrm{C}$ 'de aktivite çalışmaları yapılana kadar saklanmıştır.

Sulu etanol ekstresi: Toz hâline getirilmiş olan $5 \mathrm{~g}$ yaprak ve meyve, $\% 60$ 'lık sulu etanol ile oda sıcaklığında çalkalama maserasyonu tekniği ile ekstrakte edilmiştir. Daha sonra filtre edilerek çözücü rotavaporda $50^{\circ} \mathrm{C}^{\prime}$ yi geçmeyen sıcaklıkta kuruyuncaya kadar buharlaştırılmıştır. Ekstre $-80^{\circ} \mathrm{C}$ 'de dondurulup liyofilize edilmiştir. Liyofilize edilen materyal $-20^{\circ} \mathrm{C}$ 'de aktivite çalışmaları yapılana kadar saklanmıştır.

Kloroform ekstresi: Toz hâline getirilmiş olan $5 \mathrm{~g}$ yaprak ve meyve kloroform ile oda sıcaklığında çalkalama maserasyonu tekniği ile ekstrakte edilmiştir. Daha sonra filtre edilerek kloroform alçak basınçta kuruyuncaya kadar uçurulmuştur. Elde edilen bakiye bir miktar distile su içinde süspanse edilerek $-80^{\circ} \mathrm{C}$ 'de dondurulup liyofilize edilmiştir. Liyofilize edilen materyal $-20^{\circ} \mathrm{C}^{\prime}$ de aktivite çalışmaları yapılana kadar saklanmıştır.

Olea europaea bitkisinin ekstrelerinin sitotoksik aktivitelerinin değerlendirilmesi: $O$. europaea bitkisinin su, sulu etanol ve kloroform ekstrelerinin sito- toksik aktiviteleri için bitki ekstrelerinden 10-1.000 ppm farklı konsantrasyonlar hazırlanmıştır. WST-8 yöntemi ile sitotoksik aktiviteleri klorometrik olarak saptanmış ve istatistiksel olarak değerlendirilerek hücrelerin $\% 50$ 'sini öldüren konsantrasyon $\left(\mathrm{LC}_{50}\right)$ değerleri belirlenmiştir.

Leishmania tropica izolatının üretilmesi: Manisa Celal Bayar Üniversitesi Tıp Fakültesi Parazit Bankası'nda bulunan ülkemizden izole edilmiş MHOM/TR/2012/CBCL-LT kodlu L. tropica izolatı uygun koşullarda sıVı azot tankından çıkarılmış ve canlılık kontrolü yapıldıktan sonra Novy-Mc NealNicolle (NNN) besiyerine ekimi yapılmıştır. NNN besiyeri $26^{\circ} \mathrm{C}^{\prime}$ lik etüve kaldırılarak inkübasyona bırakılmıştır. Ekim yapıldıktan sonra ardışık günlerde besiyeri üreme açısından kontrol edilmiştir. Beşinci gün NNN besiyerinde üremesi görülen parazitler, hücre kültür flaksı içerisine konan $5 \mathrm{ml} \% 10$ "Fetal Bovine Serum" (FBS) içeren RPMI-1640 besiyerlerinin içerisine inoküle edilmiştir. Daha sonra flaks $26^{\circ} \mathrm{C}^{\prime}$ lik etüve kaldırılarak inkübasyona bırakılmıştır. Ardışık günlerde besiyeri üreme açısından kontrol edilerek parazitin üreme yoğunluğuna bakılmıştır. Üreyen ve logaritmik faza giren L. topica promastigotları $\left(10^{7}\right.$ promastigot/ml) çalışma için kullanılmıştır.

Olea europaea bitkisinin ekstrelerine karşı in vitro direnç testi: $O$. europaea bitki ekstrelerinin antileishmanial aktivitesi L. tropica promastigotları kullanılarak hemositometre yöntemi ve XTT (sodium 3,39-[1(phenylaminocarbonyl)-3,4-tetrazolium]-bis(4methoxy-6-nitro) benzene sülfonik asit hidrat) hücre proliferasyon kiti ile değerlendirilmiştir.

Çalışmamızda, 96'।ık düz tabanlı hücre kültürü plağının kuyucukları üçü blank (kör kuyucuk), üçü ilaçsız parazit kontrol, üçü amfoterisin B, üçü O. europaea bitkisi yaprak su ekstresi, üçü yaprak sulu etanol ekstresi, üçü yaprak kloroform ekstresi, üçü meyve su ekstresi, üçü meyve sulu etanol ekstresi ve üçü zeytin meyve kloroform ekstresi olacak şekilde işaretlenmiştir. Her bir kuyucuğa \%10 FBS içeren RPMI-1640 besiyerinden $100 \mu l$. konulmuştur. Direnç testi uygu- 
lanacak olan amfoterisin B ve bitki ekstreleri için ayrılmış olan üç bölmenin her birinin ilk kuyucuğuna $100 \mu \mathrm{l}$. ilave edilmiş ve ilk kuyucuktaki ilaç, bitki ekstreleri ve besiyeri homojen olacak şekilde karıştırılmıştır. Bu karışımlardan seri sulandırmalar hazırlanmıştır.

Daha sonra promastigot sayısı $10^{7}$ promastigot $/ \mathrm{ml}$ olacak şekilde Thoma lamı ile ayarlanıp, süspansiyonundan $100 \mu \mathrm{l}$. olacak şekilde bütün kuyucuklara eklenmiştir. Blank kuyucuklara parazit ilave edilmemiştir. Plağın kapağı kapatılarak etrafı parafilmle kaplanmıştır ve $26^{\circ} \mathrm{C}^{\prime}$ de 48 saat inkübe edilmiştir. Inkübasyon işleminin sonunda hemositometre ve XTT yöntemleri ile in vitro etkinlik düzeyleri belirlenmiştir. $\mathrm{Bu}$ işlem farklı zamanlarda üç kez yinelenmiştir.

Sonuçlar "Sidak's multiple comparisons" testi uygulanarak istatiksel olarak değerlendirilmiştir.

\section{BULGULAR}

Olea europaea bitkisinin su, sulu etanol ve kloroform ekstrelerinin sitotoksik aktiviteleri WST-8 yöntemi ile kolorometrik olarak saptanmış ve istatistiksel olarak değerlendirilmiştir. $O$. europaea bitkisinin meyve su, kloroform ve sulu etanol ekstreleri ile yaprak kloroform ve sulu etanol ekstreleri sitotoksik aktivite göstermemiştir. O. europaea bitkisinin yaprak su ekstresi sitotoksik aktivite göstermiş ve $\mathrm{IC}_{50} 58.45 \mu \mathrm{g} / \mathrm{ml}$ olarak belirlenmiştir.

Antileishmanial aktivitenin değerlendirilmesinde kontrol olarak amfoterisin B kullanılmış ve $\mathrm{IC}_{50}$ değeri $0.06 \mu \mathrm{M}$ olarak değerlendirilmiştir. Zeytin yaprak ve meyvenin su, sulu etanol ile kloroform ekstrelerinin antileishmanial etkisi değerlendirildiğinde, yaprak su ekstresinin IC ${ }_{50}$ değeri $6.77 \mathrm{mg} / \mathrm{kg}$, yaprak sulu etanol ekstresinin IC ${ }_{50}$ değeri $2.45 \mathrm{mg} / \mathrm{kg}$, yaprak kloroform ekstresinin $\mathrm{IC}_{50}$ değeri $6.50 \mathrm{mg} / \mathrm{kg}$, meyve sulu etanol ekstresinin $\mathrm{IC}_{50}$ değeri $4.16 \mathrm{mg} / \mathrm{kg}$ ve meyve kloroform ekstresinin IC $\mathrm{I}_{50}$ değeri $0.23 \mathrm{mg} / \mathrm{kg}$ olarak değerlendirilmiş ve meyve su ekstresinin antileishmanial aktivite göstermediği belirlenmiştir (Grafik 1).
Bu sonuçlarının ilaçsız kontrol grubu ile istatistiksel olarak karşılaştırılmasına göre meyve kloroform ekstresinin $(p<0.05)$ antileishmanial etki gösterdiği diğer ekstrelerinin etkinliğinin ise istatiksel olarak anlamlı olmadığı görülmüştür ( $p>0.05)$.

\section{TARTIŞMA}

Ülkemizde tedavide ilk tercih edilen ilaç meglumin antimonat (Glucantime ${ }^{\circledR}$ )'tır. Hindistan'ın kuzeyi başta olmak üzere dünyanın birçok yerinde meglumin antimonata karşı direncin arttığı bildirilmekte$\operatorname{dir}^{(4,5)}$. Tedavide kullanılan diğer bir ilaç ise damar yoluyla verilen ancak yan etkieri bulunan amfoterisin B'dir. Yan etkileri düşük, daha iyi tolere edilebilen ancak maliyeti pahalı olduğu için tedavi giderlerini oldukça yükselten diğer bir ilaç lipozomal amfoterisin B'dir. Günümüzde oral yolla kullanılabilen miltefosin ise özellikle gebelerde teratojenik etkiler gösterdiği için riskli kabul edilmektedir(5,6).

Leishmaniasis tedavisinde günümüzde kullanılan hiçbir aşı mevcut değildir. Ayrıca güvenli, etkili ve ucuz ilaçlara gereksinim vardır. Bu nedenle leishmaniasis tedavisinde kullanılabilecek yeni etken madde ve yeni ilaç adaylarının araştırılması gerekmektedir. Doğal bitkisel ürünler uzun yıllardır enfeksiyon hastalıklarının tedavisinde kullanılmıştır. 1981-2002 yılları arasında antiinfektif olarak onaylanan 162 yeni maddenin 99'u (\%61) doğal bitkisel üründür. Son 20 yıldır, ilaç endüstrisi doğal ürünlerin araştııııasından uzaklaşmış, yeni keşfedilen moleküler hedeflere odaklanmıştır. Ancak bu yaklaşım beklenildiği gibi verimi arttırmamış ve yeni ilaç sayısında artışa yol açmamıştır. Yeni kimyasal bileşik sayısı 2001'de tüm zamanların en düşüğü olan 37'ye düşerken, FDA'e yapılan yeni ilaç başvuruları 16 'da kalmıştır. Bu rakamlar doğal ürünlere yönelik araştırmaların ne derece önemli olduğunu ortaya koymaktadır. Günümüzde tüketiciler arasında da doğal ürünlere yönelim artış göstermektedir. Reçetesiz satılan ilaçların tüm dünyadaki toplam cirosu 1997'de 10 milyar dolar iken, bu rakamın her yıl \%6.5 artış göstereceği hesaplanmıştır. Hâlen keşfedilmeyi bekleyen çok sayıda bitkisel bileşik olduğu sanılmaktadır ${ }^{(7,8)}$. 
Yeni ilaçların geliştirilmesi ve değerlendirmesinde öncelikle tarama testlerinin ve toksisite testlerinin yapılması gerekmektedir. Tarama testleri öncelikle in vitro olarak yapılmakta ve etkili olan maddeler için in vivo testlere geçilmektedir. In vivo testlerde başarılı olan bileşiklerin toksisite testleri yapıldıktan sonra değerlendirilerek hangilerinin kullanılacağına karar verilir. Bir bileşiğin ilaç olarak değerlendirilmesi için Faz I, Faz II, Faz III ve Faz IV denemelerinden başarı ile geçmesi gerekmektedir ${ }^{(5,9)}$.

Yeni ilaçların geliştirilmesi ve değerlendirmesi sırasında özellikle antileishmanial etki gösterebilecek bileşikleri bulabilmek için bitki ekstreleri ve bunların içindeki aktif biyolojik maddeler yönünden araştırılmasının önemli olduğunu vurgulayan araştırmalar bulunmaktadır(5,10-12).

Dünya Sağlık Örgütü ve birçok araştırıcı, leishmaniasis ve diğer enfeksiyon etkenlerinin tedavisinde özellikle bölge halkının kullandığı bitkilerin gözlenip bulunarak etken madde açısından araştırılması ve tedavi için uygun bulunan etken madde ve bileşenlerinin sentetik olarak da hızla yapılabilmesi gerektiğinin vurgulamışlardır ${ }^{(5,13-15)}$. Tüm dünyada bu konuda çalışmalar başlamış, hızla sürmekte ve başarılı sonuçlar alınmaktadır. Bu çalışmalardan bazılarına bakacak olursak, ilk bitki tarama programı 1984 yılında Fransız Gine'sinde başlamış ve burada halk arasında tedavide kullanılan bitkiler çalışmaya alınmıştır. Leishmania amazonensis ile yapılan in vivo ve in vitro tarama testi çalışmalarında, Faramea guianensis bitkisinin iyi derecede antileishmanial aktivite gösterdiği saptanmıştır(16).

İspanya'da yapılan bir çalışmada, 7 bitki ailesinden 12 tür taranmış ve Inula montana, Bupleurum rigidum ve Scrophularia scorodonia türlerinin antileishmanial etki gösterdikleri saptanmıştır ${ }^{(17)}$. Kolombiya'da yapılan bir çalışmada, Annona muricata türünün Leishmania braziliensis ve Leishmania panamensis'e karşı kontrol ilacı olarak kullanılan meglumine antimoniate'den daha yüksek antileishmanial etki gösterdiği saptanmıştır ${ }^{(18)}$. Nijerya'da halk arasında tedavide kullanılan 11 bitki türünden beş tanesinin, Sudan'da sekiz bitki türünden üç tanesinin, Bolivya'da 14 bitki türünden iki tanesinin in vitro, üç tanesinin ise in vivo antileishmanial etki gösterdiği saptanmıştır ${ }^{(19-21)}$. Meksika'da yapılan bir çalışmada, 19 bitki türü antileishmanial etki yönünden taranmış ve bu bitkilerden Aphelandra scabra, Byrsonima bucidaefolia, Byrsonima crassifolia, Clusia flava, Cupania dentata, Diphysa carthagenensis, Dorstenia contrajerva, Milleria quinquefolia, Tridax procumbens ve Vitex gaumeri türlerinin Leishmania mexicana'ya karşı oldukça kuvvetli ( $\left(C_{50} 50 \mu \mathrm{g} / \mathrm{ml}\right)$ antileishmanial etki gösterdiği saptanmıştır ${ }^{(22)}$. Mali'de halk arasında geleneksel tedavide kullanılan 64 bitki türü arasında yapılan taramada, Sarcocephalus latifolius, Zanthoxylum zanthoxyloides, Entada africana, Bobgunnia madagascariensis, Pseudocereal kotschyi ve Psorospermum guineense türlerinin oldukça kuvvetli antileishmanial aktif moleküller içerdiği bulunmuştur(23).

Calophyllum brasiliense yapraklarından elde edilen kumarin yapısında madde olan (-) mammea A/BB'nin L. amazonensis'e karşı IC $\mathrm{IC}_{50}$ değerleri: 3.0 ve $0.88 \mu \mathrm{g} /$ $\mathrm{ml}$ ve $\mathrm{IC}_{90}$ değerleri: 5.0 ve $2.3 \mu \mathrm{g} / \mathrm{ml}$ olarak saptanmış ve bu yüksek bir antileishmanial etki olarak değerlendirilmiştir (24).

Achillea millefolium çiçek ve yapraklarından elde edilen uçucu yağ, L. amazonensis ve sıçan makrofajları ile in vitro aktivite yönünden araştırılmış; promastigot ve intrasellüler amastigotların hücre yapılarında antileishmanial etkinin neden olduğu bozulmalar elektron mikroskobunda gösterilmiştir ${ }^{(25)}$.

Kenya'da yapılan bir çalışmada, Allium sativum'un metanol ekstresi Leishmania major ve Leishmania donovani kullanılarak in vitro ve in vivo antileishmanial aktivitesi araştırılmış ve saptanan aktivitenin bitkinin metanol ekstrelerinin immünmodulatör etkisinden kaynaklandığı belirtilmiştir ${ }^{(26)}$.

Avusturya'da 13 bitkiden elde edilen doğal bileşikler, in vitro antileishmanial aktivite yönünden araştırıl- 
mış, visseral ve kutanöz leishmaniasis tedavisi için yeni ilaçlara kaynak olabilecek bileşiklerin varlığı gösterilmiştir ${ }^{(27)}$.

Günümüze kadar bitkisel ürünler ile yapılan çalışmalar incelendiğinde, antileishmanial etki gösteren bitki ekstrelerinin flavonoit, seskiterpen, oleanolik asit gibi triterpenik bileşikler yönünden zengin oldukları görülmektedir. Bu bileşiklerin antiprotozoal ve antimikrobiyal etki gösterdikleri yapılan çalışmalar ile gösterilmiştir. Antileishmanial aktivite yönünden araştırdığımız O. europaea bitkisinin yaprak ve meyve ekstrelerinin içerdikleri bileşikler incelendiğinde hidroksitirosol, tirozol ve benzoik asitler, oleuropein, flavonoitler, kafeik asit yanında oleanolik asit gibi triterpenoitler açısından zengin olduğu bildirilmektedir ${ }^{(28-31)}$.

Oleuropeinin promastigotlara karşı sitotoksik ve antiproliferatif etkisi olduğu ve apoptozis yoluyla promastigotları ölüme götürdüğü belirtilmektedir ${ }^{(32)}$.

Flavonoitler, antioksidan aktiviteye sahip bileşiklerdir. Aynı zamanda bazı antiparaziter özelliklerinin olduğu yayınlarda bildirilmiştir ${ }^{(33)}$.

Sifaoui ve ark.'nın ${ }^{(33)} 2014$ yılında yapmış olduğu bir çalışmaya göre, $O$. europaea bitkisinin metanol ve etanol ekstrelerinin antileishmanial aktivite gösterdiklerini ve bitkinin yaprak ekstrelerinin leishmaniasise karşı yeni bir ilaç geliştirilmesi için potansiyel yeni bileşikler taşıdıklarını bildirmişlerdir.

Kheirandish ve ark. ${ }^{(31)}$ da 2017 yılında yaptıkları bir çalışmaya göre, O. europaea bitkisinin etanol ekstresinin \%18.45 oranında oleuropein içerdiğini ve in vitro antileishmanial aktivite gösterdiğini bildirilmişlerdir.

Çalışmamızda, meyve su, kloroform ve sulu etanol ekstreleri ile yaprak kloroform ve sulu etanol ekstreleri sitotoksik aktivite göstermemişlerdir. O. europaea bitkisinin yaprak su ekstresi ( $\mathrm{LC}_{50} 58.45 \mu \mathrm{g} / \mathrm{ml}$ ) sitotoksik aktivite göstermişsir.
Olea europaea bitkisinin meyvesinden hazırlanan su, kloroform ve sulu etanol ekstreleri ile yapraklarından hazırlanan kloroform ve sulu etanol ekstrelerinin antileishmanial aktiviteleri değerlendirildiğinde sırası ile meyve kloroform ekstresi IC $C_{50}$ değeri $0.23 \mathrm{mg} / \mathrm{kg}$, yaprak sulu etanol ekstresi $\mathrm{IC}_{50}$ değeri $2.45 \mathrm{mg} / \mathrm{kg}$, meyve sulu etanol ekstresi $I C_{50}$ değeri $4.16 \mathrm{mg} / \mathrm{kg}$, yaprak su ekstresi $I C_{50}$ değeri $6.77 \mathrm{mg} / \mathrm{kg}$ ve yaprak kloroform ekstresi IC ${ }_{50}$ değeri $6.50 \mathrm{mg} / \mathrm{kg}$ olarak saptanmıştır.

Bu sonuçlarının ilaçsız kontrol grubu ile istatistiksel olarak karşılaştırıldığında meyve kloroform ekstresinin $(p<0.05)$ antileishmanial etki gösterdiği diğer ekstrelerinin anlamlı bir etkisinin olmadığı görülmüştür $(p>0.05)$.

Bu çalışmamızın sonucunda, O. europaea bitkisinin meyve kloroform ekstresinin antileishmanial aktivite göstermesi projenin amacı olan antileishmanial etken maddeler saptanması konusunda önemli ve ümit verici bir gelişme olarak değerlendirilmektedir.

\section{TEŞEKKÜR}

Bu çalışma, Manisa Celal Bayar Üniversitesi Bilimsel Araştırma Projeleri Koordinatörlüğü tarafından BAP 2018-116 numaralı proje ile desteklenmiştir.

Projenin gerçekleşmesinde Leishmania tropica izolatını sağlayan Manisa Celal Bayar Üniversitesi Tıp Fakültesi Parazit Bankası'na teşekkür ederiz.

\section{KAYNAKLAR}

1. World Health Organization. Leishmaniasis. 2019 [http://www.who.int/leishmaniasis/en]. (Erişim tarihi: 06.11.2018).

2. Felter HW, Lloyd JL. King's American Dispensatory. Cincinnati; OH: Ohio Valley Co. 1898.

3. Elliott GA, Buthala DA, DeYoung EN. Preliminary safety studies with calcium elenolate, an antiviral agent. Antimicrob Agents Chemother (Bethesda). 1969;9: 173-6.

4. Croft, SL, Yardley V. Chemotherapy of leishmaniasis. Curr Pharm Des. 2002;8(4):319-42. https://doi.org/10.2174/1381612023396258

5. Özbilgin A, Çavuş I, Yıldırım A, Kaya T, Ertabaklar H. Evaluation of In vitro and In vivo Drug Efficacy Over Leishmania tropica: A Pilot Study. Turkiye Parazitol 
Derg. 2018; 42(1):11-9. https://doi.org/10.5152/tpd.2018.5554

6. Berman J. Current treatment approaches to leishmaniasis. Curr Opin Infect Dis. 2003;16(5):397401.

https://doi.org/10.1097/00001432-200310000-00005

7. Newman DJ, Cragg GM, Snader KM. Natural products as sources of new drugs over the period 1981-2002. J Nat Prod. 2003;66(7):1022-37. https://doi.org/10.1021/np0300961

8. Rates SM. Plants as source of drugs. Toxicon. 2001;39(5):603-13. https://doi.org/10.1016/S0041-0101(00)00154-9

9. Kayaalp OS. Klinik farmakolojinin esasları ve temel düzenlemeler. Ankara; 2008:29-46.

10. de Carvalho PB, Ferreira El. Leishmaniasis phytotherapy. Nature's leadership against an ancient disease. Fitoterapia. 2001;72(6):599-618. https://doi.org/10.1016/S0367-326X(01)00301-X

11. Kayser O, Kiderlen AF. In vitro leishmanicidal activity of naturally occurring chalcones. Phytother Res. 2001;15(2):148-52. https://doi.org/10.1002/ptr.701

12. Rocha LG, Almeida JRGS, Macêdo RO, Barbosa-Filho JM. A review of natural products with antileishmanial activity. Phytomedicine. 2005;12(6-7):514-35. https://doi.org/10.1016/j.phymed.2003.10.006

13. Bhadra R. Antileishmanial agents. Drugs Fut. 1993;18(5):451-63.

14. Weniger B, Robledo S, Arango GJ, et al. Antiprotozoal activities of Colombian plants. J Ethnopharmacol. 2001;78(2-3):193-200. https://doi.org/10.1016/S0378-8741(01)00346-4

15. Carvalho PB, Arribas MAG, Ferreira El. Leishmaniasis. What do we know about its chemotherapy?. Rev Bras Cienc Farm. 2000;36(1):69-96. https://doi.org/10.1590/S0100-06832000000100009

16. Sauvain M, Dedet JP, Kunesch N, Poisson J. Isolation of flavans from the amazonian shrub Faramea guianensis. J Nat Prod. 1994;57(3):403-6. https://doi.org/10.1021/np50105a014

17. Martín T, Villaescusa L, Gasquet M, et al. Screening for protozoocidal activity of Spanish plants. Pharm Biol. 1998;36(1):56-62. https://doi.org/10.1076/phbi.36.1.56.4627

18. Jaramillo MC, Arango GJ, González MC, Robledo SM, Velez ID. Cytotoxicity and antileishmanial activity of Annona muricata pericarp. Fitoterapia. 2000;71(2): 183-6. https://doi.org/10.1016/S0367-326X(99)00138-0

19. Iwu MM, Jackson JE, Tally JD, Klayman DL. Evaluation of plant extracts for antileishmanial activity using a mechanism-based radiorespirometric microtechnique (RAM). Planta Med. 1992;58(5):436-41. https://doi.org/10.1055/s-2006-961508

20. Tahir AE, Ibrahim AM, Satti GMH, Theander TG, Kharazmi A, Khalid SA. The potential antileishmanial activity of some Sudanese medicinal plants. Phytother Res. 1998;12(8):576-9.

https://doi.org/10.1002/(SICI)1099-1573(199812)12:8 $<576$ ::AID-PTR354>3.0.CO;2-\#

21. Fournet A, Barrios AA, Muñoz V. Leishmanicidal and trypanocidal activities of Bolivian medicinal plants. J Ethnopharmacol. 1994;41(1-2):19-37.

https://doi.org/10.1016/0378-8741(94)90054-X

22. Peraza-Sánchez SR, Cen-Pacheco F, Noh-Chimal A, et al. Leishmanicidal evaluation of extracts from native plants of the Yucatan peninsula. Fitoterapia. 2007;78(4):315-8. https://doi.org/10.1016/j.fitote.2007.03.013

23. Ahua KM, loset JN, loset KN, Diallo D, Mauël J, Hostettmann K. Antileishmanial activities associated with plants used in the Malian traditional medicine. J Ethnopharmacology. 2007;110(1):99-104. https://doi.org/10.1016/j.jep.2006.09.030

24. Brenzan MA, Nakamura CV, Filho BPD, Ueda-Nakamura T, Young MC, Aparício Garcia Cortaz D. Antileishmanial activity of crude extract and coumarin from Calophyllum brasiliense leaves against Leishmania amazonensis. Parasitol Res. 2007;101(3):715-22.

https://doi.org/10.1007/s00436-007-0542-7

25. Santos AO, Santin AC, Yamaguchi MU, et al. Antileishmanial activity of an essential oil from the leaves and flowers of Achillea millefolium. Ann Trop Med Parasitol. 2010;104(6):475-83.

https://doi.org/10.1179/136485910X12786389891281

26. Wabwoba BW, Anjili CO, Ngeiywa MM, et al. Experimental chemotherapy with Allium sativum (Liliaceae) methanolic extract in rodents infected with Leishmania major and Leishmania donovani. J Vector Borne Dis. 2010;47(3):160-7.

27. Astelbauer F, Obwaller A, Raninger A, et al. Antileishmanial activity of plant-derived acridones, flavaglines, and sulfur-containing amides. Vector Borne Zoonotic Dis. 2011;11(7):793-8. https://doi.org/10.1089/vbz.2010.0087

28. Karaboğa Arslan AK, Öztürk E, Yerer MB, Koşar M. Zeytin yaprağındaki oleuropein ve farmakolojik etkileri. Sağlık Bilimleri Dergisi. 2017;26(1):89-93.

29. Altınyay Ç, Altun ML. HPLC Analysis of Oleuropein in Olea europaea. Ankara Ecz Fak Derg. 2006;35(1):1-11. https://doi.org/10.1501/Eczfak_0000000047

30. Benavente-García O, Castillo J, Lorente J, Ortuño A, Del Rio AJ. Antioxidant activity of phenolics extracted from Olea europeae L. leaves. Food Chem. 2000;68(4):45762. https://doi.org/10.1016/S0308-8146(99)00221-6

31. Kheirandish F, Delfan B, Fallahi S, Kayedi MH, Rashidipour M, Jahanbakhsh S. Leishmanicidal effects of Olea europaea Linn. extract against promastigote and amastigote forms of some Leishmania spp. Int J Pharm Sci Res. 2017;8(11):4869-74. https://doi.org/10.13040/IJPSR.0975-8232.8(11).4869-74

32. Elamin MH, Al-Maliki SS. Leishmanicidal and apoptotic activities of oleuropein on Leishmania major. Int J Clin Pharmacol Ther. 2014;52(10):880-8. https://doi.org/10.5414/CP202102

33. Sifaoui I, López-Arencibia A, Martín-Navarro C, et al. Activity of olive leaf extract against the promastigote stage of Leishmania species and their correlation with the antioxidant activity. Exp Parasitol. 2014;141:10611.

https://doi.org/10.1016/j.exppara.2014.03.002 